\title{
Ambientes de Ocorrência e Flora Acompanhante do Gênero Himatanthus em Alcântara, Maranhão, Brasil.
}

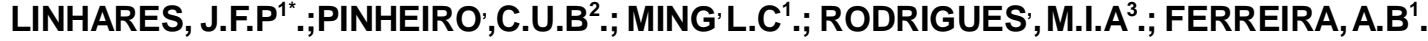
'Universidade Estadual Paulista "Júlio de Mesquita Filho"- UNESP. Departamento de Produção Vegetal, Faculdade de Ciências Agronômicas - Fazenda Experimental Lageado, Rua José Barbosa de Barros, 1780 - CEP: 18610307- Caixa-Postal: 237 - Botucatu, SP-Brasil. jairoivini29@yahoo.com.br. ${ }^{2}$ Universidade Federal do Maranhão, Departamento de Oceanografia e Limnologia, Av. dos Portugueses s/n, CEP: 65040-080, São Luis, MA-Brasil. ${ }^{3}$ Universidade Estadual do Maranhão, Departamento de Química e Biologia. Cidade Universitária Paulo VI (Tirirical), CEP: 65055-970. São Luis, MA-Brasil.
\end{abstract}

RESUMO: A janaúba (Himatanthus spp.), ocorre em populações naturais em ecossistemas florestais e apresenta amplo espectro de usos na medicina popular que vai desde o tratamento de inflamações uterinas, gastrite, uso veterinário, complemento alimentar, até tratamento de câncer. O extrativismo de látex de janaúba em Alcântara vem adquirindo importância crescente como alternativa de renda. Sendo assim, o estabelecimento de estudos que viabilizem o manejo sustentado em seu ambiente natural é necessário. O objetivo deste trabalho foi de caracterizar os ambientes de ocorrência de Himatanthus no município de Alcântara, Maranhão, Brasil, e identificar a flora acompanhante. As amostragens foram definidas por indicação de informantes, e aparente frequência na comunidade vegetal; os ambientes foram descritos considerando as unidades de paisagem e histórico de uso. Como resultados, a maior área de ocorrência foi a terra firme seguida por várzeas de restinga; a principal tipologia vegetacional foi a mata secundária. $O$ bacuri (Platonia insignis Mart.), tucum (Astrocaryum vulgare Mart.) e a murta verdadeira (Myrcia selloi (Spreng.) N. Silveira, foram às principais espécies associadas.

Palavras-chave: Himatanthus, tipologia vegetacional, Alcântara, planta medicinal.

ABSTRACT: Occurrence environments and accompanying vegetation of genus Himatanthus in Alcântara, Maranhão, Brazil. The Frangipani (Himatanthus spp.) occur in natural populations in forest ecosystems and present a wide spectrum of uses. in folk medicine ranging from the treatment of uterine inflammation, gastritis, veterinary, food supplement to medicinal treatment of cancer. The extraction of latex Janaúba Alcantara has been gaining increasing importance as an alternative income. Therefore, the establishment of studies that enable sustainable management in their natural environment is necessary. The overall objective of this study was to characterize the occurrence of Himatanthus environments in the municipality of Alcântara, Maranhão, Brazil, and identify the accompanying vegetation. The samples were defined by word of informants, and apparent frequency in the plant community, the environments were described considering the landscape units and usage history. As a result, the largest area of occurrence was followed by the mainland salt marsh wetlands, the main vegetation type was the secondary forest. Bacuri (Platonia insignis Mart.), tucum (Astrocaryum vulgare Mart.) e murta verdadeira (Myrcia selloi (Spreng.) N. Silveira, were the main species associated.

Key words: Himatanthus, vegetation typology, Alcântara, medicinal plants.

\section{INTRODUÇÃO}

O gênero Himatanthus Willd. ex Schult. é um gênero pantropical pertencente a sub-família Rauvolfioideae e a tribo Plumerieae. As espécies de Himatanthus são árvores de ramos lenhosos apresentam tronco com crescimento simpodial, com um ou mais ramos laterais em expansão na sua porção distal, dos quais um será re-orientado para a porção vertical para se tornar uma nova unidade de

Recebido para publicação: agosto de 2011

Aceito para publicação: dezembro de 2011

Rev. Bras. PI. Med., Botucatu, v.13, especial, p.550-558, 2011. 
tronco, esta forma de crescimento é denominada "Modelo de Koriba" (HALLÉ et al 1978; BELL, 1991 apud SPINA, 2004). Possui um total de nove espécies, sendo uma espécie no Panamá e oito espécies na América do Sul. As espécies de Himatanthus que ocorrem no Brasil estão distribuídas na região amazônica, na região Central em áreas de Cerrado, no Nordeste em áreas de Caatinga e Carrasco, e na região litorânea ocorre na Floresta Atlântica (SPINA, 2004; FERREIRA, 2006).

No Brasil o gênero Himatanthus, ocorre nos Estados do Amazonas, Acre, Amapá, Rondônia, Roraima, Mato Grosso, Mato Grosso do Sul, Goiás, Tocantins, Pará, Maranhão, Piauí, Ceará, Pernambuco, Rio Grande do Norte, Paraíba, Sergipe, Alagoas, Bahia, Minas Gerais, Espírito Santo, Rio de Janeiro e São Paulo (SPINA, 2004; LARROSA \& DUARTE, 2005; FERREIRA, 2006).

Em estudos mais recentes, Himatanthus obovatus (Müll. Arg.) Woodson foi considerada a espécie mais amplamente distribuída no Brasil e na Bolívia, ocorrendo principalmente em vegetação de cerrado, cerradão e campo sujo nos Estados da região Norte (Pará e Rondônia); no Nordeste, ocorre no Maranhão, Piauí, Alagoas e Bahia; no CentroOeste, em Mato Grosso, Mato Grosso do Sul, Goiás e Tocantins; e no Sudeste, em Minas Gerais e São Paulo (SPINA, 2004).

A janaúba apresenta amplo espectro de usos que vai desde o tratamento de inflamações uterinas, gastrite, uso veterinário, uso em emplastos, fortificante, complemento alimentar, até tratamento de câncer. (LINHARES, 2010).

O extrativismo de látex de janaúba em Alcântara vem adquirindo importância crescente como alternativa de renda. Sendo assim, o estabelecimento de estudos que viabilizem o manejo sustentado em seu ambiente natural é necessário.O objetivo deste trabalho foi caracterizar os ambientes de ocorrência de Himatanthus no município de Alcântara, Maranhão, Brasil, e identificar a flora acompanhante.

\section{MATERIAL E MÉTODO}

\section{Área de estudo}

O município de Alcântara, pertence à região fisiográfica do Litoral Maranhense (SEMATUR, 1991). Possui uma área total de $1.447,8 \mathrm{Km}^{2}$, população de 21.224 habitantes e densidade demográfica de 14,4 hab./ $\mathrm{Km}^{2}$. Está localizado na Mesorregião Norte Maranhense, particularmente na microrregião do litoral ocidental maranhense, na bacia do rio Pericumã. Apresenta temperatura média de $27^{\circ} \mathrm{C}$, umidade relativa do ar em torno de $82 \%$ e precipitação pluviométrica variando entre 2.000 e $2.400 \mathrm{~mm}$. O clima é do tipo Clima Úmido (c2), segundo classificação de Thorntwaite. Os solos agricultáveis são do tipo Latossolo Amarelo, apresentando baixa fertilidade natural e aptidão regular para lavoura (MARANHÃO, 1998; GEPLAN, 2002; VALLADARES et al., 2007).

Limita-se ao Norte com o Oceano Atlântico, ao Oeste com os municípios de Guimarães, Bequimão e Peri-Mirim, ao Sul com o município de Cajapió, e ao Leste com os municípios de Cajapió e São Luís, separado deste último pela baía de São Marcos e distando cerca de $22 \mathrm{Km}$ via marítima a sudeste (MARANHÃO, 1998; GEPLAN, 2002).

A comunidade litorânea de Canelatiua, objeto deste estudo, pertence ao município de Alcântara, estando situada a S $02^{\circ} 10^{\prime} 56.4^{\prime \prime}$ e W $44^{\circ} 26^{\prime}$ 38.7'. Possui uma área total estimada de 198,6 ha (não possui titulação de terras), e população de 151 habitantes distribuídos em 54 famílias. As principais fontes de renda da comunidade são aposentadorias, pensões e bolsa família (que somados, representam uma renda mensal de $R \$ 15.175,00$ distribuídas entre as 54 famílias existentes), seguidos pela agricultura de subsistência e pesca artesanal.

Caracterização das principais unidades de paisagem de ocorrência de espécies do gênero Himatanthus em Canelatiua, Alcântara, MA.

Terra Firme: o termo terra firme se aplica a todas as florestas que não são sazonalmente inundadas pelas cheias dos rios, diferenciada assim das florestas de várzea e igapó (RIBEIRO et al,1999 apud FERREIRA, 2006). Segundo Gama et al, (2005), definem a terra firme como sendo um ecossistema de maior expressividade e de grande complexidade na composição, distribuição e densidade das espécies. Apresenta relevo pouco ondulado e solo mais arenoso, dando assim condições de crescimento a uma grande quantidade de espécies. $\mathrm{Na}$ terra firme as principais tipologias vegetacionais são as matas secundárias e os babaçuais.

Várzea: de maneira geral, as várzeas amazônicas podem ser definidas como áreas alagadas basicamente por dois regimes de inundação, que são enchentes periódicas dos rios resultantes da alta pluviosidade e as enchentes diárias resultantes das marés (ARIMA \& UHL, 1996; LIMA \& TOURINHO, 1996 apud FERREIRA, 2006). $\mathrm{Na}$ área de estudo, a várzea é caracterizada por relevo plano e arenoso, próximo a curso d'água temporário e/ou intermitente e proximidade com ambiente salino sem, contudo haver influência direta do mesmo. Na unidade de paisagem de várzea, as tipologias vegetacionais principais são as matas de várzea, as matas de galeria e as restingas. 


\section{Caracterização das principais tipologias vegetacionais de ocorrência de espécies do gênero Himatanthus em Canelatiua, Alcântara, MA.}

Devido às modificações antrópicas que ocorreu sobre a cobertura florestal da comunidade de Canelatiua, a cobertura florestal anteriormente constituída pela floresta tropical subperenifolia dicótilo palmácea deu lugar, as tipologias vegetacionais hoje denominadas como florestas secundárias (capoeiras) e por babaçuais. A floresta perenifólia de várzea corresponde atualmente às matas de várzea e as restingas.

Florestas Secundárias (Capoeiras): Nas áreas de terra firme, a paisagem geral é dominada pela vegetação secundária e associações variadas em relação à composição de espécies. A composição de espécies destas formações vegetais varia em função da idade, em geral hoje entre 3-10 anos, pelo uso continuado para agricultura. Embora levantamentos neste tipo de vegetação revelem sempre um número considerável de espécies arbóreas, a maioria dos indivíduos encontra-se em estágios iniciais de crescimento ou juvenis, em função dos distúrbios continuados sobre a vegetação (particularmente desmatamentos), com muito poucos indivíduos na fase adulta. Estas formações secundárias, em associação ou não com o babaçu (Orbignya phalerata Mart.), representam hoje, o tipo de vegetação mais comum nos ambientes do município.

Babaçuais: Ainda na terra firme, a palmeira babaçu (Orbignya phalerata Mart.) tornou-se, em muitos pontos, também dominante na fitofisionomia. Trata-se também de uma floresta secundária, que substitui a floresta tropical subperenifólia anteriormente existente. Os babaçuais constituem uma cobertura vegetal que vem sofrendo acelerado processo de devastação, pela perda de seu valor econômico (extração e venda de amêndoas para a produção de óleo) quanto pelo fato de se localizar em áreas propícias à ocupação. Orbignya phalerata Mart., é a espécie de maior distribuição, de maior variação morfológica e de maior importância econômica. Ocorere em parte da Bolívia, Suriname e no Brasil, no Estado do Maranhão (encontra-se em $60 \%$ da área de ocorrência), Piauí, Ceará, Goiás, Tocantins, Mato Grosso e Pará. A área total de ocorrência do babaçu no Brasil é estimada em 15,4 milhões de hectares. A área de cobertura do babaçu no Maranhão, levantamento de 1980 , foi de 10,3 milhões de hectares (MIC/STI, 1982). Com a descaracterização de vários ambientes onde originalmente não ocorre o babaçu, como as matas de galeria, restingas e várzeas, esta palmeira avança também sobre estes ambientes.

Matas de Várzeas: Tipo de vegetação ciliar inundada por períodos curtos e frequêntes, sob a influência de marés. As matas de várzeas constituem um tipo vegetacional pouco estudado. São poucos os estudos sobre esta tipologia vegetacional, o que resulta em pouco conhecimento sobre a composição florística dos remanescentes das matas de várzea no Maranhão. O guanandi (Symphonia globuliferaL.; Clusiaceae), o mamuí ou mamorana (Pachira aquatica Aubl.; Bombacaceae ) e a ucuuba (Virola surinamensis Warb.; Myristicaceae) são espécies vegetais características deste tipo de vegetação. Apesar da menor diversidade, a mata de várzea apresenta o maior desenvolvimento estrutural. Apresentam importância ecológica por serem as áreas com maior desenvolvimento estrutural, por sua riqueza de habitats e potencial de refúgio e alimento para espécies animais. Por ser um habitat mais especializado, a mata de várzea apresenta uma diversidade menor do que a observada para as matas de terra firme. Tal como os manguezais, são áreas de preservação permanente e candidatas naturais a áreas de conservação em projetos de manejo ambiental.

Matas de Galeria: Vegetação característica das margens de pequenos cursos d'água e nascentes (ciliares e, portanto, de preservação permanente, segundo a legislação ambiental), áreas pantanosas, com vegetação higrófila característica, como buriti (Mauritia flexuosa L. f.; Palmae), juçara (Euterpe oleraceae Mart.; Palmae), guarimã (Ischnosiphon arouma (Aublet) Koern., Marantaceae) e várias espécies de Araceae, Heliconiaceae, Musaceae, entre outras Estes. ambientes se caracterizam por manterem umidade mesmo no verão, quando, em algumas áreas, são chamados de "brejos secos". Estas formações vegetacionais também vêm passando por consistente processo de pressão e descaracterização, principalmente, pelo crescimento urbano, restando alguns fragmentos ainda relativamente conservados nas áreas rurais.

Restinga: Nome dado ao conjunto de comunidades vegetais, distribuídas em mosaico, associado aos depósitos arenosos costeiros quaternários e aos ambientes rochosos litorâneos também considerados comunidades edáficas por dependerem mais da natureza do solo do que do clima. São encontradas nos ambientes de praia, cordões arenosos, dunas, depressões e transições para ambientes adjacentes, podendo apresentar, de acordo com a fitofisionomia predominante, estrato herbáceo, arbustivo e arbóreo, este último mais interiorizado (RESOLUÇÃO CONAMA N 417, 2009). No Estado do Maranhão, as restingas são constituídas por formações pioneiras que ocorrem com maior destaque nos municípios de Barreirinhas, Humberto de Campos, Icatu, Primeira Cruz e Tutóia. Em vários trechos observam-se os contatos da

Rev. Bras. Pl. Med., Botucatu, v.13, especial, p.550-558, 2011. 
restinga com dunas móveis quase sem vegetação. As restingas são arbustivas ou arbóreas, com espécies principais temos o "guajeru" (Chrysobalanus icaco L.), "alecrim-da-praia" (Polygala sp.) "salsa da praia" (Ipomea sp.) (LIMA, 1999). O autor faz menção de contatos da restinga com dunas móveis, somente a municípios pertencentes à região dos Lençóis Maranhenses.

\section{Áreas amostradas}

Os pontos de amostragem foram definidos a partir da indicação de informantes e pela aparente frequência de Himatanthus na comunidade vegetal (Tabela 1.); posteriormente foram descritos os ambientes considerando as unidades de paisagem existentes e o histórico de uso.

Por falta de referência para classificação fitofisionômica da vegetação secundária para o Estado do Maranhão, a classificação utilizada foi baseada na Resolução CONAMA № 010/1993, que estabelece parâmetros básicos para análise de estágios de sucessão da Mata Atlântica. Complementarmente, para melhor classificação da tipologia, utilizaram-se as Resoluções CONAMA № 25/1994 e 26/1994, para os Estados do Ceará e Piauí, seguindo modificações e ajustes realizados por Pinheiro (2009), com base nessa legislação, os critérios principais de distinção dos estágios sucessionais, foram: 1) Altura: Baixa (B), com indivíduos em geral de altura média abaixo dos 5 metros; Média (M), entre 5 e 15 metros; alta (A), acima dos 15 metros; 2) Densidade: Baixa (B), Média (M); Densa (D): com base no número de indivíduos por área; 3) Estágio de Regeneração: inicial ou jovem (J), para formações com menos de 5 anos; Média (M), para formações entre 5 e 15 anos; Avançado (A), para formações com mais de 15 anos.

\section{Análise fitossociológica.}

As plantas foram primeiramente identificadas pelo nome comum e posteriormente foi realizada a identificação botânica, utilizando-se procedimento padrão. A identificação das espécies da flora acompanhante foi realizada diretamente a campo e, quando esta não foi possível foi coletado material botânico para posterior identificação. Foi seguido o critério de classificação para as famílias botânicas segundo Souza \& Lorenzi (2008), baseado no sistema APG II (2003). As espécies amostradas foram identificadas por meio de literatura especializada e/ ou por comparação com as exsicatas do Herbário Rosa Mochel do Núcleo de Estudos Biológicos (NEB) da Universidade Estadual do Maranhão (UEMA). Os dados foram processados e analisados usando os programas MATA NATIVA (Cientec, 2006) e JMP (SAS, 1995).

\section{RESULTADO E DISCUSSÃO}

\section{Caracterização das áreas de ocorrência de Himatanthusspp.}

Considerando a indicação dos informantes e o histórico de uso das áreas, foram essas as principais características levantadas para as áreas amostradas:

a) Ladeira do Baixio: Relevo inclinado, solo do tipo Latossolo Amarelo com curso d'água temporário na parte mais baixa da área. A tipologia vegetal é de mata secundária com altura geral em torno de 10-12 metros, com histórico de uso agrícola em pousio nos últimos 7-8 anos; segundo os critérios adotados a classificação é MDM. Nas partes mais baixas, há ocorrência de fisionomia de restinga com presença de guajuru (Chrysobalanus icaco L.) e cebola (Clusia sp.). Na parte superior e mais plana, há ocorrência de babaçual. Atualmente o uso mais frequênte é a extração de madeira e formação de roças nas partes mais altas e planas.

b) Araraí: Relevo inclinado com solo apresentando horizonte A com textura arenosa em toda área, e camada $\mathrm{O}$, com acentuado acúmulo de serapilheira. A tipologia vegetal é de mata secundária, com altura geral em torno de 8-10 metros e histórico de uso agrícola em pousio de e" 30 anos, classificação MDA. Nas partes mais baixas da área, há ocorrência de fisionomia de restinga (Fig. 21) com presença de guajuru (Chrysobalanus icaco L..), murici (Byrsonima crassifolia Steud.) e caju (Anacardium ocidentalis L.). $\mathrm{Na}$ parte superior, limitando com uma área de chapada, há uma dominância de tucunzeiro (Astrocaryum vulgare Mart.), indicando transição para terra firme.

TABELA1. Pontos de amostragem da vegetação na localidade, Canelatiua, Alcântara, Maranhão.

\begin{tabular}{|c|c|c|}
\hline Localidade & Coordenadas & Área (ha) \\
\hline Farol & W 44 26' 33.05" e S 02 09' 45.57" & 9,84 \\
\hline Araraí & W 442ㄱ'13.46" e S $02^{\circ} 10^{\prime} 42.96^{\prime \prime}$ & 4,87 \\
\hline Ladeira do Baixio & W 4426' 59.76" e S 02 11' 15.56" & 5,36 \\
\hline Campina Grande & W 442' $02.88^{\prime \prime}$ e S $02^{\circ} 11^{\prime} 57.65^{\prime \prime}$ & 6,61 \\
\hline Total & & 26,68 \\
\hline
\end{tabular}

Rev. Bras. PI. Med., Botucatu, v.13, especial, p.550-558, 2011. 
c) Farol: Relevo inclinado, com a porção superior da área localizada em borda de falésia. Solo Podzólico com horizonte A, apresentando textura arenosa que aumenta de profundidade à medida que se distancia da borda de falésia. $O$ horizonte $\mathrm{B}$ textural $(\mathrm{Bt})$ apresenta alto teor de argila em relação ao horizonte $A$, facilitando os processos erosivos na borda de falésia, onde o horizonte A é incipiente. A tipologia vegetal é de mata secundária, altura geral em torno de 7-8 metros, e tempos de pousio superiores a 15 anos, classificação (MDA), com ocorrência de janaúba em borda de falésia, apresentando fisionomia xeromórfica devido ao horizonte A ser incipiente, provocando estresse hídrico na vegetação. Nas porções mais baixas da área, ocorrem fragmentos de capoeira com porte mais alto em decorrência do horizonte $A$ ser mais profundo. Há ocorrência também de bacurizeiro (Platonia insignis Mart.), croaçu-da-folha-grossa (Coccoloba $\mathrm{sp}$ ), campestre (Machaerium aculeatum Raddi) e araçá (Psidium kennedyanum Morong.). A área possui histórico de uso para fins de pecuária extensiva, com ocorrência em alguns trechos de queimadas anuais para formação de pastagem.

d) Campina Grande: Relevo plano com horizonte $\mathrm{A}$ apresentando textura arenosa em área de restinga antropizada, classificação (MDA), com ocorrência de plantas encontradas frequentemente em áreas perturbadas de terra firme, como quiriba [Eschweilera coriaceae (DC.) S. A. Mori], bacurizeiro (Platonia insignis Mart.) e murtas (Myrcia spp.). Está limitada por área de terra firme com presença de palmeiras de babaçu (Orbignya phalerata Mart.), e em um de seus limites com área de mata ciliar.

Flora acompanhante de Himatanthus spp.

Os levantamentos florísticos e fitossociológicos para identificação da flora acompanhante de Himatanthus foram realizados em duas unidades de paisagem (terra firme e várzea), nas duas tipologias vegetacionais principais (mata secundária e restinga) (Tabela 2).

Para identificação da flora, foi amostrado um total de 5.615 indivíduos entre jovens e adultos, de 39 famílias botânicas; 12 indivíduos não foram identificados (Tabela 3).
TABELA 3. Frequências absolutas e relativas das famílias botânicas registradas nas localidades: Ladeira do Baixio, Campina Grande, Farol e Araraí. Comunidade de Canelatiua, Alcântara, MA.

\begin{tabular}{lcc}
\hline Familias Botânicas & Fa & Fr \\
\hline Anacardiaceae & 13 & 0,232 \\
Annonaceae & 134 & 2,386 \\
Apocynaceae & 853 & 15,191 \\
Arecaceae & 607 & 10,810 \\
Bombacaceae & 36 & 0,641 \\
Boraginaceae & 5 & 0,089 \\
Bromeliaceae & 1 & 0,018 \\
Burseraceae & 43 & 0,766 \\
Caparidaceae & 1 & 0,018 \\
Chrysobalanaceae & 72 & 1,282 \\
Clusiaceae & 995 & 17,721 \\
Combretaceae & 40 & 0,712 \\
Dilleniaceae & 15 & 0,268 \\
Euphorbiaceae & 6 & 0,107 \\
Lauraceae & 4 & 0,071 \\
Lecythidaceae & 376 & 6,697 \\
Fabaceae & 211 & 3,758 \\
Malpighiaceae & 105 & 1,870 \\
Moraceae & 9 & 0,160 \\
Myristicaceae & 2 & 0,036 \\
Myrsinaceae & 117 & 2,084 \\
Myrtaceae & 631 & 11,238 \\
Ochnaceae & 18 & 0,321 \\
Opiliaceae & 38 & 0,677 \\
Polygonaceae & 155 & 2,760 \\
Rubiaceae & 250 & 4,452 \\
Sapotaceae & 504 & 8,976 \\
NI-Carne de Arraia & 1 & 0,018 \\
NI-Castanha de Burro & 1 & 0,018 \\
NI-Cumaru da Folha Miúda & 1 & 0,018 \\
Nl-Guajuruzinho & 60 & 1,069 \\
NI-Ingararoba & 3 & 0,053 \\
ANI-Joana Puçá & 35 & 0,623 \\
NI-Miri & 18 & 0,321 \\
NI-Paruru Branco & 2 & 0,036 \\
NI-Paruru Vermelho & 1 & 0,018 \\
NI-Pau de Rego & 206 & 3,669 \\
NI-Sangue de Cachorro & 5 & 0,089 \\
NI-Taquipé do Alto & 41 & 0,730 \\
\hline Total: 39 Famílias & $\mathbf{5 . 6 1 5}$ & $\mathbf{1 0 0 , 0 0}$ \\
Ni - Não identificadas & $\mathbf{1 2}$ & \\
\hline & & \\
\hline
\end{tabular}

TABELA 2. Informações gerais sobre as áreas amostradas na comunidade de Canelatiua, Alcântara, MA.

\begin{tabular}{lll}
\hline Áreas amostradas & Unidade de Paisagem & Tipologia Vegetacional \\
& & \\
\hline Ladeira do Baixio & Terra Firme & Mata Secundária \\
Campina Grande & Várzea & Restinga \\
Farol & Terra Firme & Mata Secundária \\
Araraí & Terra Firme & Mata Secundária \\
\hline
\end{tabular}

Rev. Bras. PI. Med., Botucatu, v.13, especial, p.550-558, 2011. 
As famílias mais frequêntes representam $63,96 \%$ do total de famílias registradas.

Das 79 espécies registradas 13 indivíduos não foram identificados (Tabela 4).

TABELA 4. Frequências absolutas e relativas das espécies botânicas registradas nas localidades: Ladeira do Baixio, Campina Grande, Farol e Araraí. Comunidade de Canelatiua, Alcântara, MA.

\begin{tabular}{|c|c|c|}
\hline Espécies & $\mathrm{Fa}$ & $\mathrm{Fr}$ \\
\hline Agonandra brasiliensis Miers. & 38 & 0,677 \\
\hline Alibertia edulis ( Rich.) A.Rich. & 194 & 3,455 \\
\hline Anacardium ocidentalis $\mathrm{L}$. & 4 & 0,071 \\
\hline Andira fraxinifolia Benth. & 28 & 0,499 \\
\hline Astrocaryum vulgare Mart & 286 & 5,093 \\
\hline Bauhinia glabra Jacq. & 3 & 0,053 \\
\hline Bocageopsis multiflora (Mart.) R. E. Fr. & 11 & 0,196 \\
\hline Bombacopsis glabra (Pasq.) A. Robyns & 36 & 0,641 \\
\hline Bromelia balansae Mez. & 1 & 0,018 \\
\hline Byrsonima aerugo Sagot & 56 & 0,997 \\
\hline Byrsonima crassifolia Steud. & 39 & 0,695 \\
\hline Byrsonima sp. & 10 & 0,178 \\
\hline Chimarris turbinate DC. & 2 & 0,036 \\
\hline Chrysobalanus icaco L. & 72 & 1,282 \\
\hline Clusia sp. & 11 & 0,196 \\
\hline Coccoloba $s p$ & 60 & 1,069 \\
\hline Coccoloba sp1 & 1 & 0,018 \\
\hline Cordia tetandra Aubl. & 5 & 0,089 \\
\hline Crataeva tapia L. & 1 & 0,018 \\
\hline Cybianthus sp. & 117 & 2,084 \\
\hline Diplotropis purpurea (Rich.) Amshoff & 19 & 0,338 \\
\hline Dipteryx alata Vogel & 2 & 0,036 \\
\hline Doliocarpus dentatus Standl. & 14 & 0,249 \\
\hline Duguetia furfuracea (A. St. Hil.) Saff. & 44 & 0,784 \\
\hline Eschweilera coriacea (DC.) S. A. Mori & 217 & 3,865 \\
\hline Ficus dendrocida Kunth & 9 & 0,160 \\
\hline Genipa americana L. & 13 & 0,232 \\
\hline Guettarda angelica Mart. & 7 & 0,125 \\
\hline Guettarda sp. & 16 & 0,285 \\
\hline Gustavia augusta L. & 34 & 0,606 \\
\hline Himanaea stignocarpa Mart. ex Hayne & 5 & 0,089 \\
\hline Himatanthus drasticus (Mart.) Plumel & 854 & $15,20 s$ \\
\hline Inga laurina Willd. & 4 & 0,071 \\
\hline Inga sessilis Mart. & 26 & 0,463 \\
\hline Lecythis lurida (Miers.) S. A. Mori & 125 & 2,226 \\
\hline Machaerium aculeatum Raddi & 68 & 1,211 \\
\hline Manilkara huberi (Ducke) A. Chev. & 165 & 2,939 \\
\hline Margaritaria sp. & 4 & 0,071 \\
\hline Maximiliana maripa Drude & 2 & 0,036 \\
\hline Myrcia selloi (Spreng.) N. Silveira & 244 & 4,346 \\
\hline Myrcia sp1 & 172 & 3,063 \\
\hline Myrcia sp2 & 30 & 0,534 \\
\hline Myrcia sp3 & 1 & 0,02 \\
\hline Myrcia sp4 & 1 & 0,02 \\
\hline Myrcia sp5 & 80 & 1,43 \\
\hline Ocotea sp. & 4 & 0,07 \\
\hline Orbignya phalerata Mart. & 159 & 2,83 \\
\hline Ouratea castanaefolia (DC.) Engl. & 18 & 0,32 \\
\hline Pithecellobium scalare Griseb. & 19 & 0,34 \\
\hline Platonia insignis Mart. & 968 & 17,24 \\
\hline Pouteria reticulata (Engl.) Eyma & 153 & 2,73 \\
\hline Pouteria sp & 179 & 3,19 \\
\hline Prolium heptaphyllum L. Marchand & 18 & 0,32 \\
\hline Protium sp & 24 & 0,43 \\
\hline Psidium kennedyanum Morong. & 94 & 1,67 \\
\hline
\end{tabular}

continua... continuação...

\begin{tabular}{lcc}
\hline \multicolumn{1}{c}{ Espécies } & Fa & Fr \\
\hline Psidium microcarpum Cambess. & 6 & 0,11 \\
Sapium glandulatum (Vell.) Pax. & 2 & 0,04 \\
Stryphnodendron sp. & 36 & 0,64 \\
Syagrus cocoides Mart. & 161 & 2,87 \\
Tapiripa guianensis Aubl. & 9 & 0,16 \\
Terminalia guyanensis Eichler & 40 & 0,71 \\
Tocoyena sp. & 19 & 0,34 \\
Triplaris sp. & 94 & 1,67 \\
Unonopsis lindmanii R. E. Fr. & 86 & 1,53 \\
Virola surinamensis Warb. & 2 & 0,04 \\
Vismia brasiliensis Choisy & 15 & 0,27 \\
NI-Carne de Arraia & 1 & 0,02 \\
NI-Castanha de Burro & 1 & 0,02 \\
NI-Cumaru da Folha Miuda & 1 & 0,02 \\
NI-Guajuruzinho & 60 & 1,07 \\
NI-Ingararoba & 3 & 0,05 \\
NI-Joana Puçá & 35 & 0,62 \\
NI-Miri & 18 & 0,32 \\
NI Paruru Branco & 2 & 0,04 \\
NI-Paruru Vermelho & 1 & 0,02 \\
NI-Pau de Rego & 206 & 3,67 \\
NI-Pirunga & 4 & 0,07 \\
NI-Sangue de Cachorro & 5 & 0,09 \\
NI-Taquipé do Alto & 41 & 0,73 \\
\hline Total: 79 & 5615 & 100,00 \\
NI- Não identificadas & 13 & \\
\hline
\end{tabular}

As duas mais frequêntes foram bacuri (Platonia insignis Mart.), e janaúba vermelha [Himatanthus drasticus (Mart.) Plumel] que juntas representam 32,45\% das ocorrências (Tabela 5).

TABELA 5. Frequências das espécies mais frequêntes nas localidades: Ladeira do Baixio, Campina Grande, Farol e Araraí, comunidade de Canelatiua, Alcântara, MA.

\begin{tabular}{lcc}
\hline Espécies Botânicas & Fa & Fr \\
\hline Platonia insignis Mart. & 968 & 17,24 \\
Himatanthus drasticus (Mart.) Plumel & 854 & 15,21 \\
Astrocaryum vulgare Mart. & 286 & 5,09 \\
Myrcia selloi (Spreng.) N. Silveira & 244 & 4,35 \\
NI-Pau de Rego & 206 & 3,67 \\
Eschweilera coriaceae (DC.) S. A. Mori & 217 & 3,87 \\
Alibertia edulis ( Rich.) A. Rich. & 194 & 3,46 \\
Pouteria sp. & 179 & 3,19 \\
Myrcia sp1 & 172 & 3,06 \\
Syagrus cocoides Mart. & 161 & 2,87 \\
Orbignya phalerata Mart. & 159 & 2,83 \\
Lecythis lurida (Miers) S. A. Mori & 125 & 2,23 \\
\hline
\end{tabular}

Kunz et al (2008) chamam a atenção para o fato de que a abundância de indivíduos nem sempre é proporcional ao número de espécies, ou seja, poucas espécies podem ser representadas por grandes populações ou uma única espécie pode ser muito abundante na comunidade. Esta observação também se estende às famílias, que podem

Rev. Bras. PI. Med., Botucatu, v.13, especial, p.550-558, 2011. 
apresentar alta riqueza, mas serem pouco abundantes.

Com relação à grande frequência observada de bacurizeiros (Platonia insignis Mart.) nas áreas amostradas, pode ser explicada pelas condições favoráveis a ocorrência desta espécie, pois segundo Batista \& Jardim (2006), o bacurizeiro ocorre em áreas abertas, clareiras e, principalmente, na vegetação secundária, sendo rara na floresta primária densa.

A dificuldade encontrada na identificação botânica de parte da vegetação amostrada pode ser comparada aos enfrentados em estudos de composição florística no Estado do Pará e Amazonas. Segundo Gama (2005), a dificuldade nesses Estados pode ser atribuída à falta de um banco de dados oriundo de inventário florestal sistemático da flora arbórea. Comprovando essa realidade para efeito deste estudo, não havia registros de ocorrência das espécies [Himatanthus drasticus (Mart.) Plumel] e [Himatanthus obovatus (Müll.) Arg.] para o município de Alcântara. Ambas as espécies descritas para o Estado do Maranhão, de acordo com Spina (2004), em levantamento realizado em herbários, estava circunscrita a ocorrência de $[H$. drasticus (Mart.) Plumel], somente nos municípios de Fortaleza dos Nogueiras, Carolina, Barra do Corda, Caxias, Loreto, São Raimundo das Mangabeiras, Mirador, Riacho e Sambaíba; e a ocorrência de [Himatanthus obovatus (Müll. Arg.)], restrita somente ao município de Balsas.

Ao se analisar a distribuição do número de indivíduos nas unidades de paisagem, verificouse que a terra firme foi a unidade de paisagem com o maior número de indivíduos amostrados, com $62,97 \%$ do total (Tabela 6).

Gama et al (2005) reiteram esse resultado quando afirmam que a terra firme é o ecossistema de maior expressividade e de grande complexidade na composição, distribuição e densidade das espécies.

Em se tratando do número total de indivíduos amostrados, as localidades ficaram assim distribuídas por ordem de importância: Ladeira d-o Baixio 38,06\%, Campina Grande $26,07 \%$, Araraí $21,02 \%$ e Farol $14,85 \%$. (Tabela 7).

TABELA 6: Frequências absolutas e relativas do número de indivíduos nas unidades de paisagem das localidades: Ladeira do Baixio, Campina Grande, Farol e Araraí. Comunidade de Canelatiua, Alcântara, MA.

\begin{tabular}{lcc}
\hline Unidades de Paisagem & Fa & Fr \\
\hline Terra Firme & 3536 & 62,97 \\
Várzea & 2079 & 37,03 \\
Total & 5615 & 100,00 \\
\hline
\end{tabular}

TABELA 7. Frequências absolutas e relativas dos indivíduos vegetais nas localidades de Ladeira do Baixio, Campina Grande, Farol e Araraí, com respectivas áreas; Comunidade de Canelatiua, Alcântara, MA.

\begin{tabular}{lccc}
\hline Áreas amostradas & Fa & Fr & Área (ha) \\
\hline Araraí & 1180 & 21,02 & 4,87 \\
Campina Grande & 1464 & 26,07 & 6,61 \\
Farol & 834 & 14,85 & 9,84 \\
Ladeira do Baixio & 2137 & 38,06 & 5,36 \\
Total & 5615 & 100,00 & 26,68 \\
\hline
\end{tabular}

O que pode ser observado, é que o número de indivíduos amostrados não guardou relação direta com o tamanho da área. E sim, o que define esse número, é a destinação que é dada a essas áreas associada à freqüência de uso, senão vejamos. A localidade do Farol foi a maior área em termos de extensão $(9,84 \mathrm{ha})$, sendo anualmente submetida a queimadas para formação de pastagem para o gado. Desta forma, contribuiu com o menor número de indivíduos (834). Situação contrária foi observada na localidade de Araraí, onde foi a menor área amostrada em termos de extensão (4,87 ha), sendo antigamente destinada à prática agrícola, e atualmente conta com 30 anos em estado de pousio. Desta forma, apresentou uma contribuição numericamente superior de indivíduos quando comparados a localidade do Farol.

A tipologia vegetacional que predominou nas áreas amostradas foi a mata secundária com aproximados $74 \%$ do número total de indivíduos. O que apenas confirma a condição geral observada para a região. A prática agrícola itinerante define o padrão atual da vegetação na sua condição secundária em estágios variados de regeneração segundo seu tempo de uso. A presença frequênte de janaúba nesses ambientes secundários confirma a condição dessa espécie como de sucessão, aparentemente dos estágios mais avançados (secundária tardia), embora haja indicações claras da sua presença em áreas perturbadas desde os estágios iniciais do processo de sucessão vegetal (Tabela 8.

TABELA 8. Frequências absolutas e relativas do número de indivíduos nas tipologias vegetacionais das localidades: Ladeira do Baixio, Campina Grande, Farol e Araraí. Comunidade de Canelatiua, Alcântara, MA.

\begin{tabular}{lcc}
\hline Tipologia vegetal & Fa & Fr \\
\hline Mata Secundaria & 4151 & 73,93 \\
Restinga & 1464 & 26,07 \\
Total & 5615 & 100,00 \\
\hline
\end{tabular}




\section{CONCLUSÃO}

A área prioritária de ocorrência de Himatanthus spp. foi a terra firme, muito embora também foram encontradas em áreas inundáveis como as várzeas de restinga. A principal tipologia vegetacional de ocorrência foi a mata secundária. Onde o bacuri (Platonia insignis Mart.), tucum (Astrocaryum vulgare Mart.) e a murta verdadeira (Myrcia selloi (Spreng.) N. Silveira, foram às principais espécies associadas ao gênero Himatanthus. Estas espécies pertencem ao processo de sucessão secundária, o que confirma a janaúba também como espécie secundária. O fato de apresentar-se em áreas novas de sucessão e em áreas em estágios avançados indica ser uma espécie presente nos estágios iniciais, mas que se desenvolve de forma a ocupar espaço, caracterizando-se como uma espécie tardia.

\section{REFERÊNCIA}

Arima, E.; Uhl, C. Pecuária na Amazônia Oriental: desempenho atual e perspectivas futuras. Série Amazônia, 1. IMAZON, Belém. 44p. 1996.

BATISTA, F.J.; JARDIM, M.A.G. Notas sobre a morfologia floral e a fenologia do bacurizeiro (Platonia insignis Mart.) Clusiaceae, no município de Bragança, estado do Pará. II Bol. Mus. Para. Emílio Goeldi. Ciências Naturais, v. 1, n. 1, p. 183-186, 2006.

CIENTEC. Software Mata Nativa 2: Sistema para Análise Fitossociológica, Elaboração de Inventários e Planos de Manejo de Florestas Nativas. Viçosa - MG: cientec, 2006.

FERREIRA, C. Manaus: UFAM/INPA, Aspectos morfoanatômicos, bioquímicos e genéticos de Himatanthus sucuuba Wood., em ambiente de várzea e de terra firme da bacia Amazônica 2006. 90f. Tese (Doutorado em Ciências Biológicas) Programa Integrado de Pós-Graduação em Biologia Tropical e Recursos Naturais. - INPA/UFAM, Manaus, 2006. GAMA, J.R. V. SOUZA, A.L.; MARTINS, S.V. SOUZA, D.R. Comparação entre florestas de várzea e de terra firme do Estado do Pará, Revista Árvore, Viçosa-MG, v. 29, n.4, p 607-616. 2005.

GEPLAN - GERÊNCIA DE PLANEJAMENTO E DESENVOLVIMENTO ECONÔMICO. Atlas do Maranhão. Laboratório de Geoprocessamento - UEMA, São Luis, 2002. 44p.

JMP, Statistics and Graphics Guide, Version 3.2.6, (computer software and manual). SAS. Institute Inc., Cary, North Carolina. 1995.

KUNZ, S.H.; IVANAUSKAS, N.M.; MARTINS, S.V.; SILVA, E.; STEFANELLO, D. Aspectos florísticos e fitossociológicos de um trecho de Floresta Estacional Perenifólia na Fazenda Trairão, Bacia do Rio das Pacas, Querência - MT. Acta Amazônica, vol. 38(2) 245-254. 2008.

LARROSA, C.R. R.; DUARTE, M.R. Contribuição ao estudo anatômico do caule de Himatanthus sucuuba (Spuce ex Müll. Arg.). Woodson, Apocynaceae. Revista
Brasileira de Farmacognosia, p. 110-114. 2005.

LINHARES, J. F. P. L. Sustentabilidade sócio-ambiental da extração de janaúba (Himatanthus Willd. Ex Schult.) no município de Alcântara, MA, Brasil. São Luis, UFMA. 116f. 2010. Dissertação (Sustentabilidade de Ecossistemas). Programa de Pós-graduação em Sustentabilidade de Ecossistemas. Departamento de Oceanografia e limnologia. Universidade Federal do Maranhão. São Luis. 2010

MARANHÃO. SECRETARIA DE ESTADO DO MEIO AMBIENTE E RECURSOS HÍDRICOS. COORDENADORIA DE PROGRAMAS ESPECIAIS. PROGRAMA ESTADUAL DE GERENCIAMENTO COSTEIRO. Macrozoneamento do Golfão Maranhense; Diagnóstico Ambiental do Município de Alcântara. Estudo Sócio-Econômico e Cultural. - São Luís: Sema/ MMA/PNMA, 1998.

MIC / STI. Mapeamento de levantamento do Potencial de ocorrência de Babaçuais. Estados do Maranhão, Piauí, Mato Grosso e Goiás. Ministério da Indústria e do Comércio / Secretaria de Tecnologia Industrial. Brasília, 1982.

PINHEIRO, C.U.B. In: Estudo de Impacto Ambiental (EIA), Relatório de Impacto Ambiental (RIMA) e Análise de Risco Relacionado à Implantação de Refinaria de Petróleo no Município de Bacacabeira-MA. Meio Biótico - Vegetação. PETROBRÁS. São Luis, MA. 63p. 2009.

SEMATUR, Diagnóstico dos principais problemas ambientais do Estado do Maranhão. São Luis, 194p. 1991.

SOUZA V.C.; LORENZI H. Botânica Sistemática - guia ilustrado para identificação das famílias de Fanerógamas nativas e exóticas no Brasil. baseado em APG II. 2 ${ }^{a}$ Edição. Nova Odessa SP: Instituto Plantarum, 2008. 704p.

SPINA, A.P. Estudos taxonômico, micro-morfológico e filogenético do gênero Himatanthus Willd. ex Schult. (Apocynaceae: Rauvolfioideae - Plumerieae). Campinas: UNICAMP. 2004. 191f. Tese (Doutorado em Biologia Vegetal) Programa de Pós-graduação em Ciências Biológicas. Departamento de Botânica. Universidade Estadual de Campinas. Campinas, 2004. VALLADARES, G.S.; QUARTAROLI, C.F.; HOTT, M.C.; MIRANDA, E.E. de; NUNES, R. da S.; KLEPKER, D.; LIMA, G.P. Mapeamento da aptidão agrícola das terras do Estado do Maranhão. Campinas: Embrapa Monitoramento por Satélite, 2007. 25 p., il. (Boletim de Pesquisa e Desenvolvimento, 6).

RESOLUÇÃO CONAMA N 10, de 1 de outubro de 1993. Estabelece os parâmetros básicos para análise dos estágios de sucessão de Mata Atlântica. Publicada no DOU no 209, de 3 de novembro de 1993, Seção 1, páginas 16497-16498.

RESOLUÇÃO CONAMA N²5, de 7 de dezembro de 1994a. Define vegetação primária e secundária nos estágios inicial, médio e avançado de regeneração da Mata Atlântica, a fim de orientar os procedimentos de licenciamento de atividades florestais no Estado do Ceará. Publicada no DOU nำ248, de 30 de dezembro de 1994, Seção 1, páginas 21346-21347.

RESOLUÇÃO CONAMA N ${ }^{\circ} 26$, de 30 de dezembro de 1994b. Define vegetação primária e secundária nos estágios inicial, médio e avançado de regeneração da 
Mata Atlântica, a fim de orientar os procedimentos de licenciamento de atividades florestais no Estado do Piauí. Publicada no DOU no 248, de 30 de dezembro de 1994, Seção 1, página 21347.

RESOLUÇÃO CONAMA № 417, DE 23 DE NOVEMBRO DE 2009. Dispõe sobre parâmetros básicos para definição de vegetação primária e dos estágios sucessionais secundários da vegetação de Restinga na Mata Atlântica e dá outras providências. (Publicação - Diário Oficial da União - 24/11/2009). Disponível em: h t t p : / / w w w . m ma . gov.br/port/con a ma / legiabre.cfm?codlegi $=617$ 